\title{
Denplan publishes white paper on the future of dentistry
}

Denplan, part of Simplyhealth, has published a white paper on the future of dentistry.

This report covers a wide range of issues that Denplan wants to highlight and put on the agenda of government, policy makers and the wider dental profession. Using Denplan's extensive experience and clinical knowledge, as a leading voice of private dentistry in the UK, the white paper explores the five key areas of challenges and opportunities facing the private dental sector (including mixed, NHS and private practices) over the coming 12 months and beyond, including:

$\rightarrow$ The understanding of private dentistry

$\rightarrow$ The impact of COVID-19 on the sector

$\rightarrow$ Oral health and its impact on general health

$\rightarrow$ Innovation in the sector $\rightarrow$ The dental profession: workforce, mental health, professional development.

The report also makes a series of 14 recommendations to government to help address these matters and improve the nation's oral health.

Commenting on the white paper, Catherine Rutland, Clinical Director at Simplyhealth said: 'Denplan's white paper is an important and exciting opportunity to place private dentistry at the forefront of the debate about the future of healthcare and ensure the voice of private dental practices is heard.

'The Government needs to play a more active role in communicating to the public the importance of dental hygiene and routine check-ups in maintaining oral health, during the pandemic and beyond. Whilst there has been an increase in demand for urgent and emergency care, there has been a significant drop in patients attending routine dentistry due to stay at home restrictions. This will serve to grow the backlog of demand dentists need to meet in the next 12 months.

'The right thing to do is to support the profession and for the Government to recognise the specific impact of Covid-19 on private dentistry and its potential impact on patient's oral care. We would like the Government to recognise the role played by private dentists in tackling the current backlog of cases.'

The publication of Denplan's white paper comes at an interesting juncture for the dental profession and oral healthcare. The recent publication of the Government's white paper Integration and Innovation, combined with the impact of Covid-19 on the health system, means that how healthcare is delivered and accessed is changing.

\section{Updated 2020 guidelines for lower third molar management gives 'fresh approach' to patient care}

An expert working group has updated the 20-year-old National Institute for Health and Care Excellence (NICE) guidelines for lower third molar surgery to give them a fresh approach to patient care, explaining that retaining third molars can often have a detrimental impact on patients.

The group, led by Consultant Oral and Maxillofacial Surgeon (OMFS) Geoff Chiu, Professor Paul Coulthard Consultant in Oral Surgery at Barts Health NHS Trust and Specialist in Oral Surgery Professor

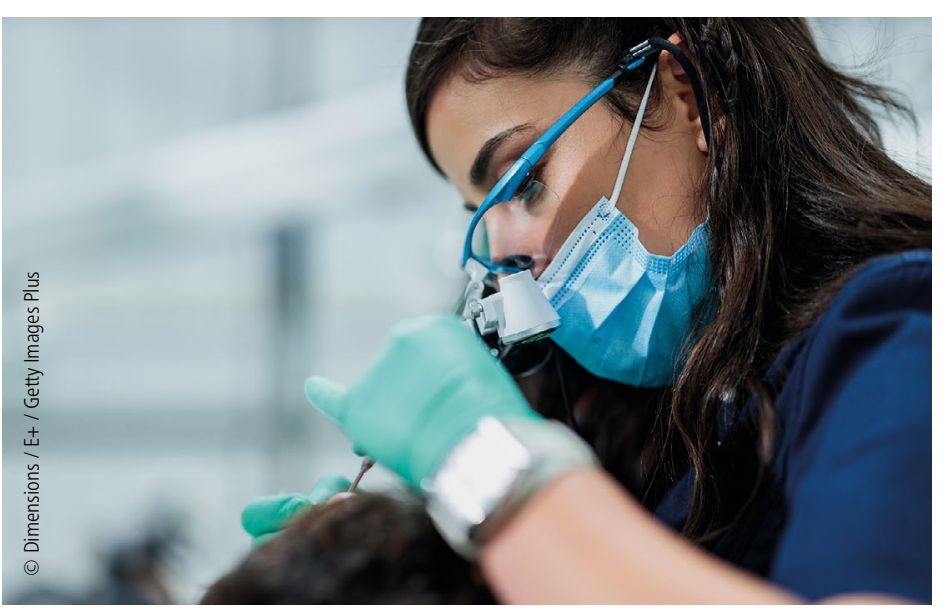

Tara Renton based at King's College London, updated the guidelines for lower third molar surgery that were originally published in 1999.

Parameters of care for patients undergoing mandibular third molar surgery (see below for link to guidelines) has recently been published by the Faculty of Dental Surgery Clinical Standards Committee (Royal

College of Surgeons of England).

Geoff Chiu said: 'Over these 20 years we have been able to see the effects that NICE guidelines have had on the oral health of patients in the UK. The new guidelines take into account all the developments since the NICE guidelines were published. This includes management of 'high risk' third molars, the current status of patient's social wellbeing and their involvement in the decision-making.'

Since 1999 there have been developments, advancements and research in: technology (Cone beam CT scans); pharmacology (steroids and local anaesthetics); and outcomes in supreme court judgements (Lanarkshire vs Montgomery) all of which have changed the management of third molars.

The East Lancashire and Bolton NHS Trusts-based OMFS Geoff Chiu says that retaining third molars in some patients has had a detrimental impact: 'This has led to patients developing latent caries or periodontal disease, which can often result in the loss of both the third and second molars.'

He is also concerned that many studies have shown the removal of third molars in older age can cause surgical morbidity that increases with age.

'The updated guidelines provide a fresh approach to the comprehensive management of third molars, Chiu concluded. 